Provided by the author(s) and University of Galway in accordance with publisher policies. Please cite the published version when available.

\begin{tabular}{|c|c|}
\hline Title & $\begin{array}{l}\text { Does a social media abstinence really reduce stress? A } \\
\text { research-in-progress study using salivary biomarkers }\end{array}$ \\
\hline Author(s) & Whelan, Eoin \\
\hline $\begin{array}{l}\text { Publication } \\
\text { Date }\end{array}$ & $2019-10-24$ \\
\hline $\begin{array}{l}\text { Publication } \\
\text { Information }\end{array}$ & $\begin{array}{l}\text { Whelan Eoin. (2020) Does a Social Media Abstinence Really } \\
\text { Reduce Stress? A Research-in-Progress Study Using Salivary } \\
\text { Biomarkers. In: Davis F., Riedl R., vom Brocke J., Léger PM., } \\
\text { Randolph A., Fischer T. (eds) Information Systems and } \\
\text { Neuroscience. Lecture Notes in Information Systems and } \\
\text { Organisation, vol 32. Springer, Cham. } \\
\text { https://doi.org/10.1007/978-3-030-28144-1_2 }\end{array}$ \\
\hline Publisher & Springer \\
\hline $\begin{array}{l}\text { Link to } \\
\text { publisher's } \\
\text { version }\end{array}$ & https://doi.org/10.1007/978-3-030-28144-1_2 \\
\hline Item record & http://hdl.handle.net/10379/16357 \\
\hline DOI & http://dx.doi.org/10.1007/978-3-030-28144-1_2 \\
\hline
\end{tabular}

Downloaded 2023-04-26T10:57:37Z

Some rights reserved. For more information, please see the item record link above. 


\title{
Does a social media abstinence really reduce stress? A research-in-progress study using salivary biomarkers
}

\author{
Eoin Whelan \\ Business Information Systems, National University of Ireland, Galway, Ireland \\ eoin.whelan@nuigalway.ie
}

\begin{abstract}
There is much scientific evidence in recent years indicating that our 'always on' culture powered by platforms such as Facebook, LinkedIn, Instagram, Twitter, and WhatsApp, is leading to negative health outcomes, particularly stress. To mitigate social media induced stress, people are being advised to abstain from using social media for a period of time. However, the effectiveness of such breaks is open to question. As many people are heavily dependent on social media, the inability to access these platforms for a period of time could actually create stress and anxiety. To determine if and how social media abstinence relates to stress, this project will investigate the role of passion as a mediating variable. Stress will be measured using a combination of the salivary biomarkers cortisol and alpha amylase, with psychological scales. Ultimately, this study aims to determine the boundary conditions under which an abstinence from social media use will either increase or decrease stress levels in working professionals.
\end{abstract}

Keywords: Social media; stress; abstinence; cortisol; alpha amylase

\section{Introduction}

Combining biomarkers of stress (cortisol and alpha amylase) with psychological measures, the objective of this study is to determine how an abstinence from social media use affects the wellbeing of working professionals. This proposed study will focus on working professionals as they are a population who are heavily dependent on social media for work, family, and leisure activities, yet are understudied in terms of the resulting health implications (1).

Social media use is increasing across society, and its association with mental wellbeing remains unclear. Some recent social media studies report on its harmful association with stress (2), anxiety (3), and depression (4). Other studies conclude the health implications of social media use to be minimally detrimental $(5,6)$, and even beneficial in some cases $(7,8)$. Notwithstanding the lack of scientific clarity, many national and organisational health policies have emerged, as well as a sizable digital detox industry, advising social media users to abstain from use for a period of time. For example, the Royal Society for Public Health now advocate a "Scroll Free September". While such policies may be well intentioned, they are in essence untested medical interventions. 
Given the contemporary nature of the phenomena, there is a limited body of knowledge pertaining to the health implications of social media abstinence. Many people are heavily dependent on social media $(9,10)$. Thus, removing access to a person's social media accounts for a period of time may actually increase stress and anxiety. Indeed, recent studies have validated the link between the inability to access digital technology and stress $(11)$, anxiety $(3,12)$, and sleep difficulties $(13)$. In the context of working professionals, one study found some employees worked for longer stretches when online distractions were blocked, a consequence of which was increased stress (14). Likewise, the withdrawal symptoms of craving and boredom have been reported by participants while abstaining from social media (15). Involuntary abstinence has also been studied, with research showing that participants who lost their smartphones reported negative feelings, such as boredom, anxiety, and loneliness (16). On the bright side, an experiment with 1,095 participants in Denmark, demonstrated that taking a one week break from Facebook had positive effects on life satisfaction and emotions, and such benefits were significantly greater for heavy Facebook users (17).

To determine why people respond differently to a social media abstinence, this study will examine the passion a worker has for social media, and if that explains increases of decreases in stress levels. Vallerand and colleagues (18-20) have conceptualised the passion a person feels for an activity, such as social media, as a duality. The dual model of passion (DMP) posits that an individual can have a strong inclination toward a self-defining activity that is loved, but that activity is comprised of both harmonious and obsessive dimensions $(21,22)$. Both forms of passion describe a "strong inclination toward an activity that people like, that they find important, and in which they invest time and energy" (Vallerand et al., 2003, p. 756). However, the opposing dimensions of passion differ in how they become internalised in the identity of an individual. A harmonious passion is adaptive and reflects a level of control to engage in the activity. The internalisation of the activity into the person's identity is autonomous (20). A person demonstrating harmonious passion is not compelled to do the activity and can stop at any time. Harmonious individuals observe the activity as a supplement to a well-balanced lifestyle and are not consumed by a sense of "I must, I need to" engage with the activity. They are able to bound the activity (e.g., set limits), set personal goals which are consistent with their own strengths and weaknesses, and can align and/or prioritise the activity, thus, reducing conflict with other life domains (e.g., work, family). In other words, the respective activity is in "harmony" with other aspects of person's life (23).

In cases of obsessive passion, the internalisation is driven by intrapersonal or interpersonal pressures, such as heightened self-esteem or social acceptance within a specific group (24). People demonstrating obsessive passion experience an internal compulsion to engage in the activity even when not appropriate to do so, as it goes beyond the person's self-control (23). Obsessive passion is maladaptive and is related to negative emotions such as shame (21). The activity dominates the person's identity to the extent it conflicts with other aspects of the person's life (20). IS scholars have drawn from the DMP to shed light on the effects of online gaming $(24,25)$, social media use (26), and internet activities (27). 
To extend state-of-the-art knowledge of the health effects of social media abstinence, this proposed study will combine physiological data with phycological data to measure stress. Both approaches are susceptible to validity issue, such as subjectivity, social desirability, and common method bias for psychological measures $(28,29)$, and construct reliability (30). Physiological approaches are particularly well equipped for measuring constructs people are unable to accurately self-report, such as stress (28). Previous technostress studies have used cortisol measures to determine the stress effects of systems breakdown (31), extensive media use (1), and interruptions (32). That is not to say that such physiological approaches are better than traditional selfreported methods. As physiological data cannot be manipulated by the subject, or susceptible to social desirability bias, triangulation with additional data sources can result in a more holistic representation of research constructs $(28,30)$. As advocated by Tams et al. (30), to improve validity and reliability, this study will combine physiological data with self-reported psychological measures of wellbeing.

\section{Proposed Methods}

Sixty volunteers who are fulltime working professionals will be recruited for this study. It is envisioned participants will be recent graduates of NUI Galway's MBA program. If required, snowball sampling techniques will also be employed to recruit more participants (e.g., postings on Facebook and newspapers). Working professionals are the focus of this study as some organisations have or are considering implementing social media blocking apps to reduce distractions and stress (14). Applicants will be screened for suitability against the following criteria;

- Regularly using social media at least 1 hour per day.

- Not required by employer to use social media for work purposes.

- No recent infections, or suffering from a chronic illness, or a heavy smoker, or receiving hormonal replacement treatment (all affect hormonal stress measures).

Selected volunteers will be randomly split into a control group of 30 , who do not abstain from using social media, and an experimental group of 30, who will abstain from social media use. The ecological momentary intervention (EMI) method will be adopted to achieve the project objectives i.e. experimental intervention in the natural setting during participants' everyday lives. This involves gathering data over; (a) a 2 day baseline phase where all participants use their social media as normal, (b) for the experimental group, a 2 day intervention phase where access to social media is blocked, while experimental group continue use as normal (c) a 2 day post intervention where social media can be used as normal again by all participants. To ensure consistency, data gathering for each phase will take place on the same workdays, Tuesday and Wednesday over 3 weeks.

Prior to commencing the EMI, participants will complete psychometric tests to measure variables which previous studies suggest may influence reaction to social media abstinence e.g. personality, emotional characteristics, fear of missing out, pre- 
occupation with social media, work-family segmentation preferences, boredom proneness. Harmonious and obsessive passion for social media will be measured using the 14 item DMP scale (21). For the physiological measures of stress, each day participants will passively droll into a small vial they will be provided with. Following best practice in saliva collection and analysis $(1,31)$, samples will be collected immediately upon waking in the morning before feet touch the floor, 30 minutes after waking, at noon (before lunch), and right before bedtime. Participants will be instructed how to freeze their saliva samples. This will result in 1,440 samples. Samples will be sent securely to the Biomarker Lab in Anglia Ruskin University for analysis. Stress is measured by calculating the change in levels of salivary cortisol and alpha amylase from morning to evening (i.e. the diurnal slope). The project is focusing specifically on cortisol and alpha amylase as previous studies found links between these stress biomarkers and digital technology use $(1,11)$.

Across all three phases of the EMI, the smartphone app 'Moment' will be used to objectively track social media usage. For the experimental group in the abstinence phase, the 'Freedom' app will used to block access to social media, which participants can override if necessary. From these apps, the research team will have documented evidence if the experimental group successfully completed the social media abstinence. Participants will also complete a daily questionnaire, to be completed at a specific time during each work day, designed to measure psychological perceptions of wellness including stress, anxiety, mood, and life satisfaction using well established scales (33-35) The questionnaire will also require participants to reflect on their behaviours during the abstinence. This will allow the researchers to determine if any compensatory behaviours emerged. In keeping with the objective of the project, the questionnaires will be paper based as opposed to computer mediated.

\section{Expected Outcomes}

This project will determine;

- The efficacy of a social media abstinence as a workplace health intervention.

- If rebound effects are prevalent when users end a social media abstinence.

- If possessing a harmonious or obsessive passion for social media explains why different groups of people respond differently to a social media abstinence.

- If a more nuanced intervention is needed to reduce the harmful effects of social media use on well-being, whilst also developing the framework for such interventions.

\section{References}

1. Afifi TD, Zamanzadeh N, Harrison K, Acevedo Callejas M. WIRED: The impact of media and technology use on stress (cortisol) and inflammation (interleukin IL-6) in fast paced families. Comput Human Behav. 2018;81:265-73.

2. Reinecke L, Aufenanger S, Beutel ME, Dreier M, Quiring O, Stark B, et al. 
Digital Stress over the Life Span: The Effects of Communication Load and Internet Multitasking on Perceived Stress and Psychological Health Impairments in a German Probability Sample. Media Psychol. 2017;20(1):90115.

3. Hartanto A, Yang H. Is the smartphone a smart choice? The effect of smartphone separation on executive functions. Comput Human Behav. 2016;64:329-36.

4. Lin LY, Sidani JE, Shensa A, Radovic A, Miller E, Colditz JB, et al. Association between social media use and depression amoung US young adults. Depress Anxiety. 2016;33:323-31.

5. Twenge JM, Joiner TE, Rogers ML, Martin GN. Increases in Depressive Symptoms, Suicide-Related Outcomes, and Suicide Rates Among U.S. Adolescents After 2010 and Links to Increased New Media Screen Time. Clin Psychol Sci. 2018;6(1):3-17.

6. Orben A, Przybylski AK. The association between adolescent well-being and digital technology use. Nat Hum Behav. 2019;3:173-82.

7. Chen HT, Li X. The contribution of mobile social media to social capital and psychological well-being: Examining the role of communicative use, friending and self-disclosure. Comput Human Behav. 2017;75:958-65.

8. Park N, Lee H. Social Implications of Smartphone Use: Korean College Students' Smartphone Use and Psychological Well-Being. Cyberpsychology, Behav Soc Netw. 2012;15(9).

9. Sha P, Sariyska R, Riedl R, Lachmann B, Montag C. Linking Internet Communication and Smartphone Use Disorder by taking a closer look at the Facebook and WhatsApp applications. Addict Behav Reports. 2019; Forthcomin.

10. Turel O. An empirical examination of the "vicious cycle" of facebook addiction. J Comput Inf Syst. 2015;55(3):83-91.

11. Tams S, Legoux R, Leger P-M. Smartphone withdrawal creates stress: A moderated mediation model of nomophobia, social threat, and phone withdrawal context. Comput Human Behav. 2018;81:1-8.

12. Cheever NA, Rosen LD, Carrier LM, Chavez A. Out of sight is not out of mind: The impact of restricting wireless mobile device use on anxiety levels among low, moderate and high users. Comput Human Behav. 2014;37:290-7.

13. Russo M, Bergami M, Morandin G. Surviving a Day Without Smartphones. MIT Sloan Manag Rev. 2018;59(2):6-9.

14. Mark G, Czerwinski M, Iqbal ST. Effects of Individual Differences in Blocking Workplace Distractions. CHI 2018. Montreal; 2018.

15. Stieger S, Lewetz D. A Week Without Using Social Media: Results from an Ecological Momentary Intervention Study Using Smartphones. Cyberpsychology, Behav Soc Netw. 2018;21(10):618-24.

16. Hoffner CA, Lee S, Park SJ. "I miss my mobile phone!": Self-expansion via mobile phone and responses to phone loss. New Media Soc. 2016;18:245268.

17. Tromholt M. The Facebook Experiment: Quitting Facebook Leads to Higher 
Levels of Well-Being. Cyberpsychology, Behav Soc Netw. 2016;19(11).

18. Rousseau FL, Vallerand RJ. Le rôle de la passion dans le bien-être subjectif des aînés. Rev Québécoise Psychol. 2003;24:197-211.

19. Vallerand RJ, Salvy SJ, Mageau GA, Elliot AJ, Denis PL, Grouzet FME, et al. On the role of passion in performance. J Pers. 2007;75(3):505-34.

20. Vallerand RJ. The psychology of passion: A dualistic model. Series in positive psychology. Oxford: Oxford University Press; 2015. 403 p.

21. Vallerand RJ, Mageau GA, Ratelle C, Léonard M, Blanchard C, Koestner R, et al. Les Passions de L'Âme: On Obsessive and Harmonious Passion. J Pers Soc Psychol. 2003;85(4):756-67.

22. Vallerand RJ. On the psychology of passion: In search of what makes people's lives most worth living. Can Psychol. 2008;49(1):1-13.

23. Paradis KF, Cooke LM, Martin LJ, Hall CR. Too much of a good thing? Examining the relationship between passion for exercise and exercise dependence. Psychol Sport Exerc. 2013;14(4):493-500.

24. Utz S, Jonas KJ, Tonkens E. Effects of passion for massively multiplayer online role-playing games on interpersonal relationships. J Media Psychol. 2012;24(2):77-86.

25. Przybylski AK, Weinstein N, Ryan RM, Rigby CS. Having to versus Wanting to Play: Background and Consequences of Harmonious versus Obsessive Engagement in Video Games. CyberPsychology Behav. 2009;12(5):485-92.

26. Orosz G, Vallerand RJ, Bothe B, Tóth-Király I, Paskuj B. On the correlates of passion for screen-based behaviors: The case of impulsivity and the problematic and non-problematic Facebook use and TV series watching. Pers Individ Dif. 2016;101:167-76.

27. Tosun LP, Lajunen T. Why Do Young Adults Develop a Passion for Internet Activities? The Associations among Personality, Revealing "True Self" on the Internet, and Passion for the Internet. CyberPsychology Behav. 2009;12(4):401-6.

28. Dimoka A, Banker R, Benbasat I, Davis F, Dennis A, Gefen D, et al. On the Use of Neurophysiological Tools in IS Research: Developing a Research Agenda for Neurois. MIS Q. 2012;36(3):679-702.

29. Podsakoff PM, MacKenzie SB, Lee JY, Podsakoff NP. Common method biases in behavioral research: a critical review of the literature and recommended remedies. J Appl Psychol. 2003;88(5):879-903.

30. Tams S, Hill K, Ortiz de Guinea A, Thatcher J, Grover V. NeuroISAlternative or Complement to Existing Methods? Illustrating the Holistic Effects of Neuroscience and Self-Reported Data in the Context of Technostress Research. J Assoc Inf Syst. 2014;15(10):723-53.

31. Riedl R, Kindermann H, Auinger A, Javor A. Technostress from a neurobiological perspective: System breakdown increases the stress hormone cortisol in computer users. Business and Information Systems Engineering. 2012. p. 61-9.

32. Tams S, Thatcher J, Ahuja M. The impact of interruptions on technology usage: Exploring interdependencies between demands from interruptions, 
worker control, and role-based stress. Lecture Notes in Information Systems and Organisation - Information Systems and Neuroscience - Gmunden Retreat on NeurolS. 2015. p. 19-25.

33. Cohen S, Kamarck T, Mermelstein R. A global measure of perceived stress. J Health Soc Behav. 1983;24(4):385-96.

34. Diener E, Emmons R a, Larsen RJ, Griffin S. The Satisfaction With Life Scale. J Pers Assess [Internet]. 1985;49(1):71-5. Available from: http://www.ncbi.nlm.nih.gov/pubmed/16367493

35. Rosenberg M, Schooler C, Schoenbach C, Rosenberg F. Global Self-Esteem and Specific Self-Esteem: Different Concepts, Different Outcomes. Am Sociol Rev. 1995;60(1):141-56. 